\title{
CROP PROTECTION
}

\section{Ácaros em Produtos Armazenados Comercializados em Supermercados e Feiras Livres da Cidade do Recife}

\author{
Josilene M. de Sousa, Manoel G.C. Gondim Jr., Reginaldo Barros e José V. de Oliveira \\ Depto. Agronomia, Área Fitossanidade, Universidade Federal Rural de Pernambuco, Rua Dom Manoel de \\ Medeiross/n,52171-900 Recife,PE,mguedes@ufrpe.br
}

Neotropical Entomology 34(2):303-309 (2005)

Mites in Stored Foods Commercialized in Supermarkets and Markets in Recife

\begin{abstract}
The mite fauna was assessed in bean, maize and pet food in supermarkets and markets in Recife, PE, Brazil. A $500 \mathrm{~g}$ sample of each grain and food was collected in each establishment at two weekly intervals, from August 2002 to June 2003. The sample was divided into two $250 \mathrm{~g}$ subsamples. One of them was submitted to spider mite evaluation shortly after collection and the other was incubated at $26^{\circ} \mathrm{C}$ and $78 \%$ humidity for 30 days. At the end of this period the second subsample was processed in the same way as the first. The spider mites were mounted on slides for microscopy in Hoyer medium and identified at least at genus level. Eleven thousand nine hundred and fifty-six spider mites were collected belonging to the Acaridae, Ebertiidae, Glycyphagidae, Cheyletidae, Stigmaeidae, Pyemotidae, Tarsonemidae, Tydeidae, Cunaxidae, Ameroseiidae, Ascidae e Phytoseiidae families. Among the primary spider mites the Suidasia medanensis Oudemans species was predominant in the survey (3,035 individuals) followed by Caloglyphus hughesi (Samsinak) (436 individuals). Metapronematus sp. was predominant (3,417 individuals) among the secondary spider mites followed by Tarsonemus granarius Lindquist $(3,003)$. The number of mites collected in the incubated samples was always greater compared to the non-incubated samples in both the market and supermarket samples.
\end{abstract}

KEY WORDS: Acari, stored product, diversity

RESUMO - Este trabalho teve como objetivo avaliar a acarofauna em grãos de feijão, milho e ração em supermercados e feiras livres da cidade do Recife, PE. Em cada estabelecimento foi coletada uma amostra de $500 \mathrm{~g}$ de cada grão e ração, em intervalos bimensais, no período de agosto/2002 a junho/ 2003. Cada amostra foi dividida em duas sub-amostras de $250 \mathrm{~g}$. Uma delas foi submetida à extração de ácaros logo após a coleta e a outra foi incubada a $26^{\circ} \mathrm{C}$ e umidade relativa de $78 \%$ por 30 dias. Ao final desse período a segunda sub-amostra foi processada da mesma forma que a primeira. Os ácaros foram montados em lâminas para microscopia em meio de Hoyer e identificados pelo menos até o nível de gênero. Foram coletados 11.956 ácaros pertencentes às famílias Acaridae, Ebertiidae, Glycyphagidae, Cheyletidae, Stigmaeidae, Pyemotidae, Tarsonemidae, Tydeidae, Cunaxidae, Ameroseiidae, Ascidae e Phytoseiidae. Dentre os ácaros primários, a espécie Suidasia medanensis Oudemans foi a predominante no levantamento (3.035 indivíduos), seguida de Caloglyphus hughesi (Samsinak) (436 indivíduos). Metapronematus sp. foi predominante (3.417 indivíduos), dentre os ácaros secundários, seguido de Tarsonemus granarius Lindquist (3.003). O número de ácaros coletados nas amostras incubadas foi sempre superior em relação às amostras não incubadas, assim como nas amostras de feira livre em relação às de supermercado.

PALAVRAS-CHAVE: Acari, grãos armazenados, diversidade

O ambiente artificial criado pelos depósitos e armazéns de grãos armazenados favorece o desenvolvimento de diversas espécies de ácaros, visto que a proteção contra extremos de temperatura permite a alimentação abundante e reprodução durante todo ano (Flechtmann 1986). Organismos graminívoros podem explorar a fonte de alimentação nesses depósitos com reduzida possibilidade de morte, e ao mesmo tempo fornecer alimento para grande 
variedade de predadores e organismos micófagos a eles associados (Hughes 1976).

Apesar da ocorrência de grande número de espécies de ácaros nas unidades de armazenamento em diferentes partes do mundo, poucas são capazes de causar danos aos grãos armazenados (Pacheco \& Paula 1995). De acordo com a alimentação, os ácaros são divididos em: primários (Acaridida), que se alimentam diretamente dos produtos armazenados; secundários (Gamasida e Actinedida), que compreendem os predadores e parasitos e, os terciários (Actinedida, Acaridida, Gamasida e Oribatida), que são micófagos (Krantz 1961). Os ácaros que habitam os depósitos seguem uma ordem cronológica de infestação nos produtos, ocorrendo inicialmente os primários, depois os secundários e por fim os terciários (Baggio et al. 1987). Esses ácaros são, geralmente, conduzidos por roedores, aves e insetos, que foram atraídos ou introduzidos do solo e da matéria orgânica de áreas adjacentes ou de áreas de plantio (Olsen 1983).

As condições de armazenamento podem favorecer o desenvolvimento de ácaros, estando diretamente relacionadas, entre outros fatores, com o grau de limpeza dos depósitos, umidade relativa, temperatura e infestação de insetos (Lorini 1998). O armazenamento torna-se inadequado sob condições de umidade relativa superior a 70\%, favorecendo o desenvolvimento de ácaros e microrganismos (Flechtmann 1968a).

Braga (1957) identificou ácaros que infestavam produtos armazenados no Brasil, constatando a espécie Acarus siro L. presente em punilha de queijo, que segundo Flechtmann (1986) tratava-se, provavelmente, de Tyrophagus putrescentiae (Schrank), espécie predominante em alimentos no Brasil e não $A$. siro, espécie dominante na Europa e América do Norte. Outros pesquisadores realizaram levantamentos de ácaros em produtos armazenados no Brasil, sobretudo no estado de São Paulo (Flechtmann 1968b, Reis \& Paschoal 1968, Baggio et al. 1987, Franzolin \& Baggio 2000).

O controle desses ácaros geralmente é dificultado pelo fato de eles passarem despercebidos, devido ao seu tamanho reduzido. Porém quando detectados podem ser controlados através da alteração das condições ambientais nas estruturas de armazenamento (Lorini 1998). Esses ácaros também podem ser controlados com inseticidas fumigantes, como a fosfina (Sinha et al. 1967), além de piretróides e organofosforados (Zdarkova 1994). Tem sido estudado o uso de predadores das famílias Cheyletidae e Ascidae para controle biológico de ácaros em grãos armazenados (Zdarkova \& Feit 1999, Rezk 2000), e o tratamento de grãos com óleos vegetais (Sanchez Ramos \& Castanera 2001). Essas alternativas, inclusive, vêm sendo testadas em conjunto, através do manejo integrado (Armitage et al. 1994).

Este trabalho teve por objetivo avaliar a diversidade de espécies de ácaros em grãos de feijão, milho e rações comercializadas em supermercados e feiras livres do Recife e estimar a abundância desses ácaros nos diversos estabelecimentos.

\section{Material e Métodos}

O trabalho foi realizado no laboratório de Acarologia Agrícola da Área de Fitossanidade da Universidade Federal Rural de Pernambuco (UFRPE) na cidade do Recife, PE. Foram coletadas amostras de grãos de milho (Zea mays L.) e feijão (Phaseolus vulgaris L.), e ração para cães, em três feiras livres (Casa Amarela, Cordeiro e Afogados), sob condições de armazenamento a granel e três supermercados (Carrefour, Bompreço e Comprebem), acondicionadas em embalagens hermeticamente fechadas. As coletas foram realizadas em intervalos bimensais, no período de agosto/2002 a junho/2003. Em cada local foram coletadas amostras de $500 \mathrm{~g}$ de grãos e ração. Cada amostra foi dividida em duas sub-amostras de $250 \mathrm{~g}$. Uma delas foi submetida à extração de ácaros em funil de Berlese-Thulgren por 24h logo após a coleta e a outra foi etiquetada, acondicionada em sacos plásticos e incubada a $26^{\circ} \mathrm{C}$ e $78 \%$ de umidade relativa interna dos sacos por 30 dias. Ao final desse período, a segunda sub-amostra foi processada da mesma forma que a primeira. No total foram processadas 216 amostras (seis coletas, seis locais, três tipos de produto, dois períodos de processamento após a coleta).

Depois da extração todos os ácaros coletados foram montados em lâminas para microscopia em meio de Hoyer e identificados pelo menos até o nível de gênero. As identificações foram baseadas principalmente em Hughes (1976).

Após a identificação as espécies foram agrupadas em função do produto, local de coleta, tempo para extração dos ácaros após a coleta da amostra e grupo de ácaro. Os resultados foram submetidos à análise de variância e as médias comparadas pelo do teste de Tukey a $5 \%$ de probabilidade, com o auxilio do Software SANEST 3.0. (Zonta \& Machado 1984).

As espécies também foram agrupadas por família e os índices de associação para as mais freqüentes foram calculados em função do tipo de produto e localidade; os índices de similaridade de Mountford foram calculados de acordo com Silveira Neto et al. (1976). Finalmente foi construído um dendograma baseado nas análises dos índices de similaridade.

\section{Resultados e Discussão}

Foram coletados, no período de agosto/2002 a junho/2003, 11.956 ácaros em 216 amostras de grãos e ração pertencentes as seguintes famílias: Tydeidae (30,2\%), Ebertiidae $(25,4 \%)$, Tarsonemidae $(25,1 \%)$, Acaridae $(9,5 \%)$, Cheyletidae $(4,1 \%)$, Glycyphagidae (2,2\%), Ascidae (2,2\%), Ameroseiidae $(0,9 \%)$, Pyemotidae $(0,2 \%)$, Stigmaeidae $(0,2 \%)$, Phytoseiidae $(0,1 \%)$ e Cunaxidae $(0,1 \%)$. Dentre os ácaros primários, Suidasia medanensis Oudemans foi a espécie predominante no levantamento (3.035 indivíduos), seguida de Caloglyphus hughesi (Samsinak) (436 indivíduos), Caloglyphus oudemansi (Zachvatkin) (422 indivíduos) e T. putrescentiae (250 indivíduos). Dentre os secundários, Metapronematus sp. foi predominante (3.417 indivíduos), seguido de Tarsonemus granarius Lindquist (3.003 indivíduos), Cheyletus spp. (465 indivíduos) e Blattisocius keegani Fox (253 indivíduos). A diversidade de espécies foi maior dentre os ácaros secundários (dezesseis espécies), que nos ácaros primários (oito espécies) (Tabela 1). 
Tabela 1. Abundância de ácaros em produtos armazenados comercializados em supermercados e feiras livres da cidade do Recife, PE, no período de agosto/2002 a junho de 2003.

\begin{tabular}{|c|c|c|c|c|c|c|c|c|c|c|c|c|c|c|}
\hline \multirow{2}{*}{ Espécies } & \multicolumn{2}{|c|}{ Agosto } & \multicolumn{2}{|c|}{ Outubro } & \multicolumn{2}{|c|}{ Dezembro } & \multicolumn{2}{|c|}{ Fevereiro } & \multicolumn{2}{|c|}{ Abril } & \multicolumn{2}{|c|}{ Junho } & \multirow{2}{*}{ Total } & \multirow{2}{*}{$\%$} \\
\hline & T0 & $\mathrm{T} 1$ & T0 & $\mathrm{T} 1$ & T0 & $\mathrm{T} 1$ & T0 & $\mathrm{T} 1$ & T0 & $\mathrm{T} 1$ & T0 & $\mathrm{T} 1$ & & \\
\hline \multicolumn{15}{|l|}{ ACARIDIDA } \\
\hline Acaridae & & & & & & & & & & & & & & 9,47 \\
\hline $\begin{array}{l}\text { Caloglyphus hughesi } \\
\text { (Samsinak) }\end{array}$ & 0 & 0 & 0 & 0 & 0 & 0 & 0 & 0 & 0 & 0 & 0 & 436 & 436 & 3,75 \\
\hline $\begin{array}{l}\text { Caloglyphus oudemansi } \\
\text { (Zachvatkin) }\end{array}$ & 0 & 0 & 0 & 0 & 0 & 0 & 0 & 0 & 12 & 3 & 0 & 407 & 422 & 3,53 \\
\hline Caloglyphus sp. & 0 & 0 & 0 & 0 & 0 & 0 & 0 & 0 & 6 & 0 & 0 & 2 & 8 & 0,07 \\
\hline $\begin{array}{l}\text { Rhizoglyphus callae } \\
\text { Oudemans }\end{array}$ & 3 & 0 & 0 & 0 & 0 & 0 & 0 & 0 & 0 & 0 & 0 & 0 & 3 & 0,03 \\
\hline $\begin{array}{l}\text { Tyrophagus putrescentiae } \\
\text { (Schrank) }\end{array}$ & 0 & 0 & 4 & 1 & 0 & 0 & 0 & 2 & 10 & 11 & 62 & 160 & 250 & 2,09 \\
\hline Ebertiidae & & & & & & & & & & & & & & 25,83 \\
\hline $\begin{array}{l}\text { Suidasia medanensis } \\
\text { Oudemans }\end{array}$ & 32 & 6 & 49 & 1763 & 87 & 384 & 4 & 20 & 11 & 199 & 235 & 245 & 3035 & 25,38 \\
\hline Glycyphagidae & & & & & & & & & & & & & & 2,22 \\
\hline $\begin{array}{l}\text { Austroglycyphagus } \\
\text { geniculatus (Vitzthum) }\end{array}$ & 0 & 5 & 12 & 10 & 14 & 7 & 0 & 1 & 4 & 1 & 0 & 99 & 153 & 1,30 \\
\hline \multicolumn{14}{|l|}{ ACTINEDIDA } & 0,92 \\
\hline Cheyletidae & & & & & & & & & & & & & & 4,11 \\
\hline Bak sp. & 1 & 0 & 0 & 0 & 2 & 0 & 0 & 0 & 0 & 0 & 0 & 0 & 3 & 0,03 \\
\hline $\begin{array}{l}\text { Cheyletus malaccensis } \\
\text { Oudemans }\end{array}$ & 10 & 9 & 8 & 54 & 4 & 6 & 0 & 1 & 19 & 15 & 33 & 10 & 169 & 1,41 \\
\hline Cheyletus sp. & 7 & 44 & 9 & 54 & 3 & 10 & 3 & 5 & 48 & 21 & 64 & 28 & 296 & 2,48 \\
\hline $\begin{array}{l}\text { Ker bakeri Zaher \& } \\
\text { Soliman }\end{array}$ & 5 & 13 & 0 & 1 & 0 & 0 & 0 & 0 & 0 & 0 & 2 & 1 & 22 & 0,18 \\
\hline Cunaxidae & & & & & & & & & & & & & & 0,04 \\
\hline $\begin{array}{l}\text { Amascirus } s p \text {. } \\
\text { Pyemotidae }\end{array}$ & 0 & 0 & 0 & 0 & 0 & 0 & 0 & 0 & 0 & 1 & 0 & 4 & 5 & $\begin{array}{l}0,04 \\
0,23\end{array}$ \\
\hline $\begin{array}{l}\text { Acarophenax tribolii } \\
\text { Newstead }\end{array}$ & 0 & 0 & 1 & 0 & 1 & 0 & 0 & 0 & 0 & 0 & 0 & 0 & 2 & 0,02 \\
\hline $\begin{array}{l}\text { Pyemotes sp. } \\
\text { Stigmaeidae }\end{array}$ & 1 & 3 & 1 & 1 & 0 & 0 & 0 & 3 & 0 & 0 & 12 & 4 & 25 & $\begin{array}{l}0,21 \\
0,22\end{array}$ \\
\hline Apostigmaeus sp. & 12 & 5 & 0 & 0 & 0 & 0 & 0 & 0 & 0 & 0 & 0 & 6 & 23 & 0,19 \\
\hline Barbutia sp. & 4 & 0 & 0 & 0 & 0 & 0 & 0 & 0 & 0 & 0 & 0 & 0 & 4 & 0,03 \\
\hline Tydeidae & & & & & & & & & & & & & & 30,23 \\
\hline Lorryia sp. & 20 & 149 & 1 & 1 & 2 & 0 & 0 & 3 & 0 & 0 & 0 & 21 & 197 & 1,65 \\
\hline Metapronematus sp. & 70 & 202 & 4 & 4 & 2 & 0 & 1 & 350 & 132 & 1996 & 29 & 627 & 3417 & 28,58 \\
\hline Tarsonemidae & & & & & & & & & & & & & & 25,12 \\
\hline $\begin{array}{l}\text { Tarsonemus granarius } \\
\text { Lindquist }\end{array}$ & 74 & 204 & 5 & 1 & 0 & 0 & 24 & 186 & 63 & 1024 & 177 & 1245 & 3003 & 25,12 \\
\hline GAMASIDA & & & & & & & & & & & & & & \\
\hline Ameroseiidae & & & & & & & & & & & & & & 0,86 \\
\hline $\begin{array}{l}\text { Kleemannia plumigera } \\
\text { Oudemans }\end{array}$ & 3 & 11 & 0 & 0 & 0 & 4 & 0 & 2 & 9 & 4 & 8 & 62 & 103 & 0,86 \\
\hline Ascidae & & & & & & & & & & & & & & 2,17 \\
\hline Blattisocius keegani Fox & 5 & 14 & 2 & 0 & 0 & 18 & 1 & 8 & 8 & 10 & 12 & 175 & 253 & 2,12 \\
\hline $\begin{array}{l}\text { Blattisocius tarsalis } \\
\text { (Berlese) }\end{array}$ & 1 & 2 & 0 & 0 & 1 & 0 & 0 & 0 & 0 & 0 & 2 & 0 & 6 & 0,05 \\
\hline Phytoseiidae & & & & & & & & & & & & & & 0,07 \\
\hline Amblyseius sp. & 0 & 0 & 0 & 6 & 0 & 0 & 0 & 0 & 0 & 0 & 0 & 2 & 8 & 0,07 \\
\hline ORIBATIDA & 0 & 1 & 0 & 0 & 0 & 0 & 0 & 0 & 0 & 2 & 0 & 0 & 3 & 0,03 \\
\hline Total & & & & & & & & & & & & & 11.956 & \\
\hline
\end{tabular}

T0, Avaliação logo após a coleta; T1, Avaliação 30 dias após a coleta. 
O presente trabalho é pioneiro no levantamento de espécies de ácaros em produtos armazenados no Nordeste do Brasil, embora diversas espécies encontradas neste levantamento já tenham sido constatadas em outros trabalhos realizados para o estado de São Paulo. Flechtmann (1968b) coletou os ácaros T. putrescentiae, Caloglyphus sp. $S$. medanensis, Glycyphagus sp., Cheyletus malaccensis Oudemans e Tydeus sp. em material de fundo de depósito de arroz, feijão e ração. Reis \& Paschoal (1968) verificaram a presença de Rhizoglyphus sp., Tyrophagus sp., Blattisocius tarsalis (Berlese), Proctolaelaps pygmaeus (Müller), Cheletomorpha lepidoptorum (Shaw.), Eutogenes sp., Stratiolaelaps sp., Tasrsonemus sp. e Tydeus kochi Oudemans. Baggio et al. (1987) avaliaram a positividade de ácaros primários e secundários em 160 amostras de cereais, e verificaram que os ácaros primários $T$. putrescentiae, Aleuroglyphus ovatus (Tropeau), Glycyphagus domesticus (DeGeer) apresentaram frequências de 48, 18 e 7\%, respectivamente; os ácaros secundários Tarsonemus sp., C. malaccensis e Ascidae tiverem freqüência de 11,8 e $5 \%$, respectivamente. Franzolin \& Baggio (2000) avaliaram a contaminação de arroz e feijão armazenado na cidade de São Paulo e verificaram que as espécies dominantes foram $T$. putrescentiae, B. tropicalis, Cheyletus spp. e B. tarsalis.

Ocorreu maior número de ácaros nas amostras incubadas que nas não incubadas $(P>0,05)$, independentemente do produto e grupo de ácaro (Fig. 1), exceto para os Cheyletidae na $5^{\mathrm{a}}$ e $6^{\mathrm{a}}$ coletas. Houve maior número de ácaros nas amostras de feiras livres que nas de supermercados $(\mathrm{P}>$ $0,05)$, independentemente do produto e do tempo de processamento após a coleta da amostra, exceto para feijão não incubado (Fig. 2).

O número de ácaros coletados nas amostras incubadas por 30 dias foi superior ao das não incubadas, evidenciando que em maior o tempo de exposição dos grãos, em condições favoráveis de temperatura e umidade relativa, pode ocorrer aumento considerável no número de ácaros. Franzolin \& Baggio (2000) não verificaram a presença de ácaros em amostras de feijão e arroz armazenado no estado de São Paulo logo após a coleta, contudo após a incubação das amostras por 42 dias a $25^{\circ} \mathrm{C}$ e $75 \%$ de umidade relativa verificaram a presença de ácaros em $31,7 \%$ das amostras.

$\mathrm{O}$ fato de a quantidade de ácaros coletados em grãos oriundos de feira livre ser maior que em supermercado devese, provavelmente, ao armazenamento a granel feito nas feiras livres que, deve favorecer a dispersão e contaminação do material armazenado. Segundo Houck \& Oconnor (1991), os ácaros astigmatas apresentam relações foréticas com outros organismos, sobretudo insetos da ordem Coleoptera, Hymenoptera e Diptera, podendo os insetos auxilia-los no processo de dispersão. Além disso, nos supermercados o ambiente é refrigerado, com menor temperatura e menor umidade relativa, condições que devem reduzir a velocidade de desenvolvimento e reprodução dos ácaros. Thind \& Clarke (2001) afirmaram que a acarofauna depende, principalmente, das condições de armazenamento nas fábricas, da origem e processamento dos produtos.

Franzolin \& Baggio (2000) verificaram que a ocorrência
Feijão

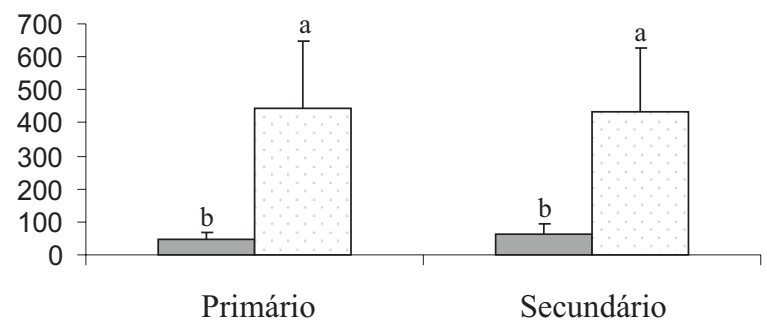

Milho

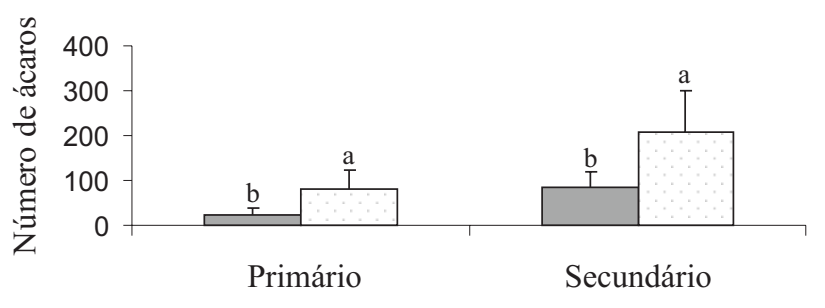

Ração

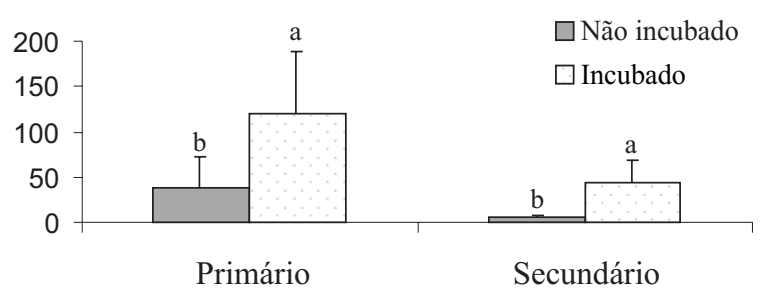

Figura 1. Número médio de ácaros primários e secundários coletados em amostras de grãos milho, feijão e ração não incubadas e incubadas, obtidas em supermercados e em feiras livres da Cidade do Recife, PE. Colunas seguidas pela mesma letra, dentro de cada grupo de ácaros, não diferem estatisticamente $(\mathrm{P}>0,05)$.

de ácaros em grãos de feijão e arroz na cidade de São Paulo foi maior no verão, quando a temperatura e umidade relativa são maiores que em outras épocas do ano. Contudo, Matsumoto et al. (1998), estudando o processo de dispersão de várias espécies de astigmatas verificaram que todas foram dispersas mais ativamente em condições de menor umidade relativa, e os ácaros estudados apresentaram dois comportamentos diferentes em relação à temperatura: um grupo (Lardoglyphus konoi (Sasa \& Asanuma), G. domesticus e Acarus immobilis Griffiths) foi mais ativamente disperso em altas temperaturas $\left(35^{\circ} \mathrm{C}\right)$ e o outro grupo (Carpoglyphus lactis L. e T. putrescentiae) foi mais ativo em baixas temperaturas $\left(15-20^{\circ} \mathrm{C}\right)$. Hubert et al. (2003) verificaram que além de o aumento da umidade relativa propiciar o desenvolvimento de ácaros, como para A. siro e T. putrescentiae, também favorece a proliferação de fungos que lhes servem de alimento.

As condições ambientais, forma de estocagem, estado físico dos grãos, circulação de ar, acumulação de vegetais 


\section{Feijão}
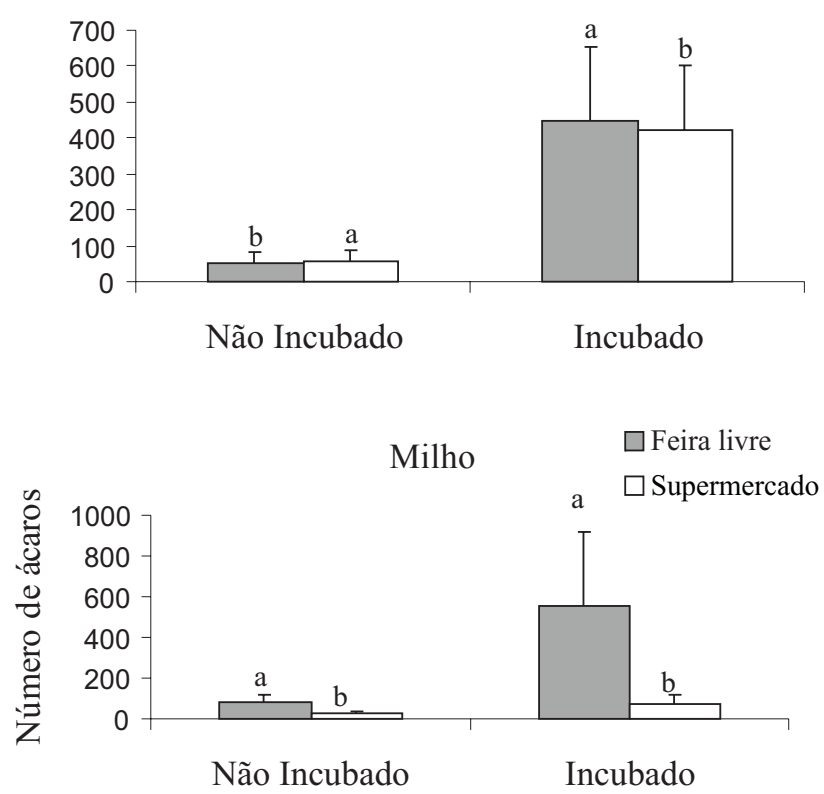

Ração

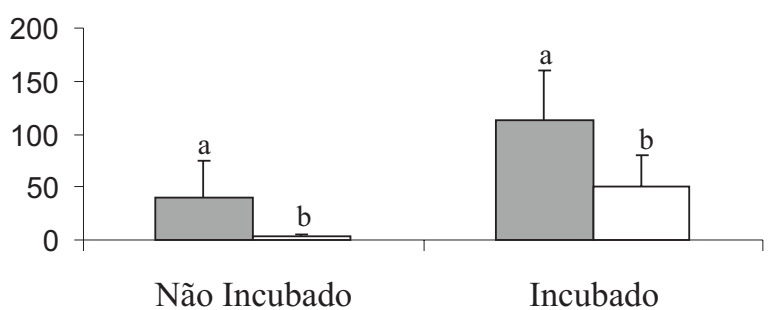

Figura 2. Número médio de ácaros coletados em amostras de grãos de milho, feijão e ração incubadas e não incubadas, obtidas em supermercados e em feiras livres da Cidade do Recife, PE. Colunas seguidas pela mesma letra, dentro de cada grupo de ácaros, não diferem estatisticamente $(\mathrm{P}>0,05)$.

nos depósitos, dentre outros fatores, podem favorecer o desenvolvimento de ácaros (Sinha 1979, Lorini 1998). Segundo Mercado et al. (2001), temperatura de $26^{\circ} \mathrm{C}$ e umidade relativa de $86 \%$ podem ser consideradas ótimas para o desenvolvimento de $S$. medanensis, comum em ambientes tropicais, sendo essa a espécie de ácaro primário mais abundante no presente levantamento.

Os índices de associação calculados entre as famílias Acaridae, Ascidae, Ebertiidae e Tydeidae apresentaram valores negativos e próximos de -1 (Tabela 2). A baixa associação entre essas famílias pode ser justificada, em parte, pelo fato de a maioria dos ácaros estar concentrada em apenas três famílias (Tydeidae 30,2\%, Ebertiidae 25,4\% e Tarsonemidae 25,1\%). Além disso, as famílias Acaridae e Ebertiidae são representadas por ácaros primários, que por apresentarem o mesmo hábito alimentar podem estar competindo por alimento.

A associação positiva com maior valor foi entre Tarsonemidae e Tydeidae $(0,534)$ (Tabela 2$)$ e isso pode estar ligado ao fato de esses ácaros compartilharem, comumente, o mesmo hábito alimentar, que inclui a ingestão de fungos (Hughes 1976, Sinha 1979). Os ácaros da família Tarsonemidae, principalmente a espécie T. granarius, e os da família Tydeidae são associados com fungos dos gêneros Penicillium, Aspergillus, Chaetomium e Hormodendrum e com outros ácaros (Hughes 1976). O segundo maior índice positivo de associação foi entre as famílias Ebertiidae (primário) e Cheyletidae (secundário), o que pode indicar uma ação de predação dos ácaros do gênero Cheyletus sobre os do gênero Suidasia. Segundo Hughes (1976), os Cheyletidae que ocorrem em grãos armazenados alimentamse comumente de ácaros astigmatas, sobretudo daqueles da família Acaridae. Pulpan \& Verner (1965) avaliaram o controle de ácaros astigmatas, principalmente $A$. siro, através da introdução do ácaro Cheyletus eruditus (Schrank) em oito diferentes tipos de grãos armazenados e concluíram que esse predador tem potencial para uso no controle biológico de ácaros em produtos armazenados. Zdarkova \& Pulpan (1973) demonstraram que populações de C. eruditus podem ser mantidas em grãos a baixas temperaturas para posterior uso no controle biológico de alguns ácaros primários. Recentemente, outros autores também têm demonstrado a possibilidade de uso de ácaros da família Cheyletidae para o controle de astigmatas (Zdarkova \& Voracek 1993, Zdarkova, 1994, Zdarkova \& Feit 1999) ou no manejo integrado de pragas de grãos utilizados em conjunto com outras técnicas (Zdarkova et al. 2003).

C. malaccensis é uma das espécies de ácaros secundários mais citadas em levantamentos de ácaros em grãos armazenados no Brasil (Flechtmann 1968b, Baggio et al. 1987, Franzolin \& Baggio 2000), e dentre as espécies

Tabela 2. Índices de associação entre famílias de ácaros mais comuns coletados em supermercados e feiras livres da cidade do Recife, PE.

\begin{tabular}{lccccc}
\hline & Acaridae & Cheyletidae & Tydeidae & Tarsonemidae & Ascidae \\
\hline Ebertiidae & $-0,973$ & 0,224 & $-0,772$ & $-0,499$ & $-0,900$ \\
Acaridae & - & $-0,787$ & $-0,950$ & 0,074 & $-0,989$ \\
Cheyletidae & - & - & $-0,072$ & 0,182 & $-0,500$ \\
Tydeidae & - & - & - & 0,534 & $-0,784$ \\
Tarsonemidae & - & - & - & - & $-0,378$ \\
Ascidae & - & - & - & - & - \\
\hline
\end{tabular}


primárias, S. medanensis foi a mais abundante neste levantamento, portanto, provavelmente, é uma das fontes de alimento de $C$. malaccensis em ambientes de armazenamento nas condições da cidade do Recife, PE.

Ácaros da família Ascidae também têm sido relatados como inimigos naturais de ácaros (Rezk 2000) e, sobretudo de insetos em grãos armazenados (Nielsen 2001, Mashaya 2002). Rezk (2000) avaliou o efeito de B. keegani no controle biológico de $T$. putrescentiae e Blomia freemani Hughes e mostrou que o número de presas consumidas por fêmea foi de 40 e 35, respectivamente. $O$ autor afirmou, ainda, que $B$. keegani apresenta potencial para o uso no controle biológico. No Brasil, ácaros do gênero Blattisocius vêm sendo registrados em alguns trabalhos (Reis \& Paschoal 1968, Franzolin \& Baggio 2000) e, provavelmente, em estabelecimentos comerciais do Recife, B. keegani esteja alimentando-se de ácaros astigmatas e, sobretudo de ovos de insetos-praga de grãos armazenados.

Os insetos e ácaros interagem no ecossistema dos produtos armazenados, e essa interação depende, basicamente, dos hábitos alimentares de ambos. Segundo Mashaya (2002), os ácaros secundários alimentam-se, geralmente, de ácaros primários, podendo ainda predar insetos como Liposcelis sp. e Rhyzopertha dominica (Fabr.). Ácaros como Pyemotes tritici (Lagrèze-Fossat \& Montagné) parasitam larva e pupa de Sitotroga cerealella (Oliver). A espécie Tribolium confusum Jaquelin Du Val é parasitada por Acarophenax tribolii Newstead (Krantz 1961), e B. tarsalis preda ovos de Ephestia, Sitotroga e Plodia (Nielsen 2003).

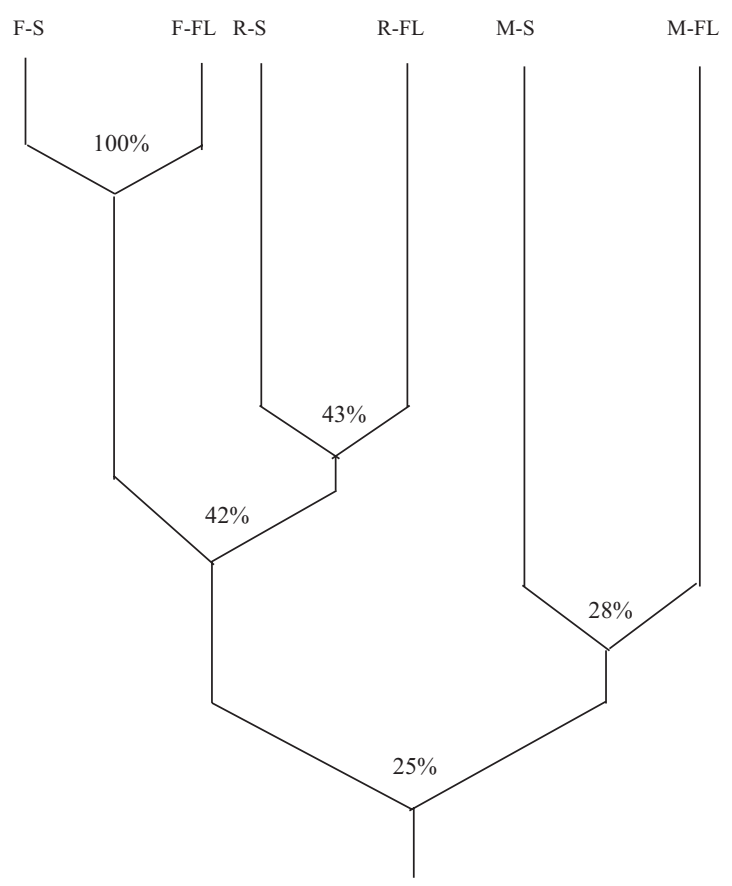

Figura 3. Dendograma resultante da análise dos índices de similaridade em grãos de milho, feijão e ração coletados em supermercados e feiras livres da cidade do Recife, PE. (F - Feijão; R - Ração; M - Milho; S - Supermercado; FL - Feira Livre).
A classificação das faunas de milho, feijão e ração para cães oriundas de feiras livres e supermercados na cidade do Recife (Fig. 3) evidenciou maior similaridade entre o tipo de produto, que entre o local de amostragem (supermercado ou feira livre) e as condições de armazenamento (granel ou em sacos hermeticamente fechados).

Embora tenham sido coletados quase 12.000 ácaros pertencentes a 26 espécies, a maioria das amostras apresentou número reduzido de ácaros, demonstrando que as condições de armazenamento nos locais amostrados não têm favorecido o desenvolvimento desses artrópodes e que, provavelmente, ácaros predadores como $C$. malaccensis e $B$. keegani estão diretamente envolvidos com o controle biológico de ácaros primários, sobretudo $S$. medanensis em feijão, milho e ração em estabelecimentos comerciais na cidade do Recife.

\section{Agradecimentos}

Ao CNPq pela concessão de bolsa ao primeiro autor, possibilitando a realização deste trabalho.

\section{Literatura Citada}

Armitage, D.M., P.M. Cogan \& D.R. Wilkin. 1994. Integrated pest management in stored grain: Combining surface insecticide treatments with aeration. J. Stored Prod. Res. 30: 303-319.

Baggio, D., S.M. Figueiredo, C.H.W. Flechtmann, G.Q. Zambon \& S.H.G. Miranda. 1987. Avaliação da presença de ácaros em cereais armazenados na grande São Paulo. An. E.S.A. "Luiz de Queiroz”. 44: 617-626.

Braga, F.M. 1957. Catálogo dos ácaros que vivem nas plantas cultivadas e nos produtos armazenados no Brasil. Bol. Fitos. 7: 31-44.

Flechtmann, C.H.W. 1968a. Considerações acerca da fisiologia em ácaros de produtos armazenados. Solo 60 : 79-80.

Flechtmann, C.H.W. 1968b. Notas sobre ácaros de produtos armazenados. Solo 60: 63-65.

Flechtmann, C.H.W. 1975. Ácaros de importância agrícola. São Paulo, Nobel, 189p.

Flechtmann, C.H.W. 1986. Ácaros de produtos armazenados e na poeira domiciliar. Piracicaba, FEALQ, 97p.

Franzolin, M.R. \& D. Baggio. 2000. Contaminação por ácaros em arroz polido e feijão comercializados a granel. Rev. Saúde Pública 34: 77-83.

Houck M.A. \& B.M. Oconnor. 1991. Ecological and evolutionary significance of phoresi in the Astigmata. 
Rev. Ann. Entomol. 36: 611-636.

Hubert, J., V. Stejskal, A. Kubatova, Z. Munzbergová, M. Vanová \& E. Zdarkova. 2003. Mites as selective fungal carries in stored grain habitats. Exp. Appl. Acarol. 29: 69-87.

Hughes, A.M. 1976. The mites of stored food and houses. London, Min. Agric. Fish. Food, 400p.

Krantz, G.W. 1961. The biology and ecology of granary mites of the Pacific Northwest I. Ecological considerations. Ann. Entomol. Soc. Am. 54: 169-174.

Lorini, I. 1998. Controle integrado de pragas de grãos armazenados. Passo Fundo, EMBRAPA-CNPT, 52p. (EMBRAPA-CNPT. Documentos, 48).

Mashaya, N. 2002. Predation of the booklouse Liposcelis entomophila (Enderlein) by Blattisocius dentriticus. (Berlese) and their susceptibility to deltamethrin an fenitrothion. Insect Sci. Appl. 22: 75-79.

Matsumoto, K., M. Okamoto., H. Horikawa., K. Nakagawa., H. Yamaura \& Y. Kuwahara. 1998. The effects of the different environmental conditions on the dispersion of grain and house dust mites (Acari: Astigmata). Med. Entomol. Zool. 49: 291-300.

Mercado, D., P. Leonardo \& L. Caraballo. 2001. Lifecycle of Suidasia medanensis (=pontifica) (Acari: Suidasiidae) under laboratory conditions in a tropical environment. Exp. Appl. Acarol. 25: 751-755.

Nielsen, P.S. 2001. Developmental time of Blattisocius tarsalis (Acari: Ascidae) at different temperatures. Exp. Appl. Acarol. 25: 605-608.

Nielsen, P.S. 2003. Predation by Blattisocius tarsalis (Berlese) (Acari: Ascidae) on eggs of Ephestia kuehniella Zeller (Lepidoptera: Pyralidae). J. Stored Prod. Res. 39: 395-400.

Olsen, A.R. 1983. Food-contaminating mites from imported foods entering the United States through southern California. Int. J. Acarol. 9: 189-193.

Pacheco, I.A. \& D.C. Paula. 1995. Insetos de grãos armazenados identificação e biologia. Campinas, Fundação Cargil, 228p.

Pulpan, J. \& P.H. Verner. 1965. Control of Tyroglyphoid mites in stored grain by the predatory mite Cheyletus eruditus (Schrank). Can. J. Zool. 43: 419-431.

Reis, A.E. \& A.D. Paschoal. 1968. Alguns ácaros de produtos armazenados do estado de São Paulo. Solo 60: 73-74.

Rezk, H.A. 2000. Mites associated with stored dried-dates in Egypt and the role of Blattisocius keegani Fox as a biological control agent. Alexandria J. Agric. Res. 45: 179-191.

Sanchez Ramos. I. \& P. Castanera. 2001. Acaricidal activity of natural monoterpenes on Tyrophagus putrescentiae (Schrank), a mite of stored food. J. Stored Prod. Res. 37: 93-101.

Silveira Neto, S., O. Nakano, D. Barbin \& N.A. Villa Nova. 1976. Manual de ecologia dos insetos. São Paulo, Agronômica Ceres, 419p.

Sinha, R.N. 1979. Role of acarina in the stored grain ecosystem. Recent Adv. Acarol. 1: 263-271.

Sinha, R.N., B. Berck \& H.A.H. Wallace. 1967. Effect of phosphine on mites, insects and microorganisms. J. Econ. Entomol. 60: 125-132.

Thind, B.B. \& P.G. Clarke. 2001. The occurrence of mites in cereal-basead foods destined for human consumption and possible consequences of infestation. Exp. Appl. Acarol. 25: 203-215.

Zdarkova, E. 1994. The effectiveness of organophosphate acaricides on stored product mites interacting in biological control. Exp. Appl. Acarol. 18: 747-751.

Zdarkova, E., J. Lukas \& E. Horak. 2003. Compatibility of Cheyletus eruditus (Schrank) (Acari: Cheyletidae) and Cephalonomia tarsalis (Ashmead) (Hymenoptera: Bethylidae) in the biological control of stored grain pests. Plant Prot. Sci. 39: 29-34.

Zdarkova, E. \& J. Pulpan. 1973. Low temperature storage of the predatory mite Cheyletus eruditus (schrank) for future use in biological control. J. Stored Prod. Res. 9: 217-220.

Zdarkova, E. \& R. Feit. 1999. Biological control of stored mites on oilseeds using the mites predator Cheyletus eruditus (Schrank). Plant Prot. Sci. 35: 136-138.

Zdarkova, E \& V. Voracek. 1993. The effects of physical factors on survival of stored food mites. Exp. Appl. Acarol. 17: 197-204.

Zonta, E.P. \& A.A. Machado. 1984. Sistema de análise estatística para microcomputadores (SANEST). Pelotas, RS: Instituto de Física e Matemática, UFPel. 